\title{
Safety and efficacy of testosterone gel in the treatment of male hypogonadism
}

This article was published in the following Dove Press journal:

Clinical Interventions in Aging

8 October 2009

Number of times this article has been viewed

\author{
Kishore M Lakshman \\ Shehzad Basaria \\ Section of Endocrinology, Diabetes, \\ and Nutrition. Boston University \\ School of Medicine, Boston Medical \\ Center, Boston, MA, USA
}

\begin{abstract}
Transdermal testosterone gels were first introduced in the US in 2000. Since then, they have emerged as a favorable mode of testosterone substitution. Serum testosterone levels reach a steady-state in the first 24 hours of application and remain in the normal range for the duration of the application. This pharmacokinetic profile is comparable to that of testosterone patch but superior to injectable testosterone esters that are associated with peaks and troughs with each dose. Testosterone gels are as efficacious as patches and injectable forms in their effects on sexual function and mood. Anticipated increases in prostate-specific antigen with testosterone therapy are not significantly different with testosterone gels, and the risk of polycythemia is lower than injectable modalities. Application site reactions, a major drawback of testosterone patches, occur less frequently with testosterone gels. However, inter-personal transfer is a concern if appropriate precautions are not taken. Superior tolerability and dose flexibility make testosterone gel highly desirable over other modalities of testosterone replacement. Androgel and Testim, the two currently available testosterone gel products in the US, have certain brandspecific properties that clinicians may consider prior to prescribing.
\end{abstract}

Keywords: testosterone gel, Androgel, Testim, hypogonadism

\section{Physiology of hypothalamic-pituitary-gonadal axis}

Testicular function is dependent on the hypothalamic secretion of gonadotropin-releasing hormone $(\mathrm{GnRH})$ which in turn stimulates the secretion of follicle-stimulating hormone (FSH) and luteinizing hormone (LH) from the pituitary to act on the testis. This results in spermatogenesis and testosterone production via stimulation of seminiferous tubules and Sertoli cells, and Leydig cells, respectively. Testosterone is secreted at adult levels during three periods of male life: transient surge during the first trimester of intrauterine life, perinatal surge during early neonatal life, and continually after puberty to maintain androgenization. Testosterone exerts negative feedback both at the level of the hypothalamus and the pituitary gland. Additionaly, sertoli cells produce inhibin that exerts a negative feedback on FSH secretion.

\section{Diagnosis of androgen deficiency}

The estimates of the prevalence of androgen deficiency, defined solely in terms of serum testosterone concentrations below the lower limit of the normal range for healthy young men, vary greatly among different studies. Longitudinal data from the Massachusetts Male Aging Study (MMAS) indicate that the prevalence of symptomatic androgen deficiency (Total testosterone $<300 \mathrm{ng} / \mathrm{dL}$ ) in men aged between $40-69$ years is between $6 \%$ and $12 \% .^{1}$ In the Baltimore Longitudinal Study of Aging (BLSA), the prevalence

submit your manuscript | www.dovepress.con 
of low total testosterone levels (testosterone $<325 \mathrm{ng} / \mathrm{dL}$ ) increased from relatively low levels for men aged less than 49 years to $12 \%, 19 \%, 28 \%$, and $49 \%$ in men in their 50 's, 60's, 70's, and 80's, respectively. ${ }^{2}$ Cross-sectional data from the Boston Area Community Health (BACH) Survey estimate the prevalence of symptomatic androgen deficiency (testosterone $<300 \mathrm{ng} / \mathrm{dL}$ and free testosterone $<5 \mathrm{ng} / \mathrm{dL}$ ) to be $5.6 \%$ in men aged between 30 and 79 years. $^{3}$

Androgen deficiency is a clinical syndrome complex that comprises symptoms and signs in conjunction with biochemical evidence of testosterone deficiency. Several professional societies have published guidelines for the diagnosis and treatment of androgen deficiency. These include the American Association of Clinical Endocrinologists (AACE) ${ }^{4}$ the Endocrine Society, ${ }^{5}$ the International Society of Andrology (ISA), European Association of Urology (EAU), European Academy of Andrology (EAA), and the American Society of Andrology (ASA). ${ }^{6}$

According to the Endocrine Society guidelines of 2006, diagnosis of androgen deficiency should be made only in men with consistent symptoms and signs and unequivocally low serum testosterone levels. ${ }^{5}$ The diagnostic evaluation of men with androgen deficiency proceeds in three steps. The first step includes evaluation of general health, lifestyle, and the use of recreational drugs such as alcohol, marijuana, opiates, and cocaine, and exclusion of systemic illnesses or medications that might affect testicular function such as cimetidine, spironolactone, and glucocorticoids. The second step is the measurement of total testosterone level, preferably in the morning, using a reliable assay. If the total testosterone level is low, this should be confirmed by repeating the measurement of morning total testosterone and in some patients (eg, obese and elderly men) by calculation or measurement of free or bioavailable testosterone. The third step in the diagnostic evaluation is to determine whether androgen deficiency is the result of a primary testicular dysfunction or secondary to a hypothalamic or pituitary disorder. This is best accomplished by measurement of serum LH and FSH levels. Elevated LH and FSH levels in association with low testosterone levels indicate primary testicular failure, while low or inappropriately normal gonadotropins in association with low testosterone levels indicate either a hypothalamic-pituitary defect or a dual defect. Measurements of prolactin and iron studies are also important aspects of evaluation.

Several complexities render the application of these guidelines into clinical practice difficult. To start with, the signs and symptoms of androgen deficiency in men are nonspecific and vary with the age of onset of androgen deficiency, its severity and duration, associated co-morbidities, genetic differences in androgen sensitivity, and previous testosterone therapy. ${ }^{5,7,8}$ Additionally, the measurement of serum testosterone levels by commercial immunoassays have been fraught with problems. Fortunately, liquid chromatography tandem mass spectrometry, widely considered gold standard for total testosterone measurement, is now being adopted by some commercial labs. The assays for the measurement of free or bioavailable testosterone are also fraught with problems. Most of the circulating testosterone is bound to sex hormone-binding globulin (SHBG) and albumin; only 0.5 to $2 \%$ of circulating testosterone is free which can be measured by equilibrium dialysis. Bioavailable testosterone denotes free testosterone plus albuminbound testosterone. Bioavailable testosterone is measured by the ammonium sulfate precipitation method. Both free and bioavailable testosterone concentrations can also be calculated from total testosterone, albumin, and SHBG concentrations using the law of mass action equations. ${ }^{9,10}$ The Endocrine Society's Expert Panel concluded that calculation of free testosterone concentration from reliably measured total testosterone and SHBG using the law of mass action equations provides the best approach for the estimation of free testosterone concentration. ${ }^{11}$ Since bioavailable testosterone is a multiple of calculated free testosterone value, it does not provide any additional information than that derived from calculated free testosterone.

\section{History of testosterone therapy}

The first historic evidence that testosterone contributed to virility came form the early experiment of Berthold in 1849 when he transplanted testes from roosters in the abdomen of capons (castrated roosters) and observed that animals with transplanted testes behaved like normal roosters. ${ }^{12}$ They were noted to fight among themselves and showed an inclination towards hens. He reported that "these animals remained male in regards to voice, reproduction instinct, and growth of comb and wattles." Following Berthold's observation, there were several experiments using testicular extracts. The best known are those by Brown-Sequard (1889), when he injected testicular extracts from testicles of dogs and guinea pigs on himself at the age of $72 .{ }^{13} \mathrm{He}$ claimed "a remarkable return of physical strength and endurance, a rejuvenated bowel system, and enhanced mental capacity." Vornoff transplanted testes from animals to humans in the 1930's for the purpose of rejuvenation, but the effectiveness of his methods was refuted by the Royal Society of London. ${ }^{14}$ Further milestones in androgen replacement were made with 
the isolation of steroidal androgens by Butenandt (1931), extraction of testosterone in a crystalline form from bull testes by David and colleagues (1935), and the chemical synthesis of testosterone by Butenandt and Hanish (1935), and Rizica and Wettstein (1935). ${ }^{15}$ Since testosterone per se was ineffective orally due to high first-pass metabolism in the liver, the initial forms of replacement was its alkylated form: $17 \alpha$-methyl testosterone. Alternatively, testosterone was compressed into pellets and implanted subcutaneously. The era of longer acting injectable testosterone esters began in the 1950's and quickly became the preferred modality of replacement. ${ }^{16}$ In the late 1970 's, the orally effective testosterone undecanoate became available. ${ }^{17}$ In the mid 1990's, transdermal testosterone patches became available. These were applied either to the scrotal ${ }^{18}$ or nonscrotal skin. ${ }^{19}$ In 2000, the first transdermal testosterone gel (Androgel) became available for androgen replacement, initially in the US, and subsequently in other countries. ${ }^{20}$ In 2004, an injectable form of testosterone undecanoate that demonstrated a superior pharmacokinetic profile ${ }^{21}$ to other injectable preparations became available in Europe. Testosterone undecanoate is currently undergoing clinical trials in the United States. In this paper, we will only review the safety and efficacy of testosterone gel in the treatment of male hypogonadism.

\section{Testosterone gel}

The need for a transdermal testosterone gel arose to overcome the drawbacks of the other delivery systems. For instance, injectable esters were associated with peaks and troughs of serum testosterone outside the physiological range, patches were associated with a high incidence of application site reactions, and pellets were associated with the risk of extrusion and infection.

The two commercially available forms of testosterone gel in the US are Androgel and Testim (1\%) gels. Inactive ingredients in AndroGel are carbomer 980, ethanol (67.0\%), isopropyl myristate, purified water, and sodium hydroxide. ${ }^{22}$ Inactive ingredients in Testim are purified water, pentadecalactone, carbopol, acrylates, propylene glycol, glycerin, polyethylene glycol, ethanol (74\%), and tromethamine. ${ }^{23}$ Androgel is available in metered-dose pumps and packets. The metered-dose pump delivers $1.25 \mathrm{~g}$ of testosterone when the lever is fully depressed once. Androgel packets are available in $2.5 \mathrm{~g}$ and $5 \mathrm{~g}$ dosing options. Testim gel is available as a single dose (tube) containing $5 \mathrm{~g}$ of the product.

The recommended starting dose of testosterone gel is $5 \mathrm{~g}$ /day and this provides a nominal delivery of $5 \mathrm{mg}$ /day ( $1 \%)$ of testosterone systemically. Serum testosterone levels should be monitored serially to ensure proper dosing. If serum testosterone concentration is below the normal range or if the desired clinical response is not achieved, the dose may be increased from $5 \mathrm{~g}$ to $7.5-10 \mathrm{~g}$. It is recommended that testosterone gel be applied early morning on intact dry skin over the shoulders, upper arms or in case of Androgel, the abdomen as well. Patients are advised to wash their hands well after application, allow the application site to dry for a few minutes and to cover the site with clothing. It is recommended to wait for four hours prior to showering or swimming. Application sites must to be washed with soap and water if skin-to-skin contact of these areas is anticipated with another person.

\section{Pharmacokinetics of testosterone gel}

When an open system of hydroalcoholic gel of a steroid is applied to the skin, the steroid is rapidly absorbed into the stratum corneum, which forms a reservoir and acts as a rate-controlling membrane. The steroid then gradually diffuses from this skin reservoir over several hours, reaching steady-state levels in the serum. ${ }^{24}$ In 2000, Androgel became available for treatment of male hypogonadism in the US. Wang and colleagues ${ }^{20}$ demonstrated that application of $10 \mathrm{~g} /$ day of Androgel (applied either entirely at one site or at four different sites) resulted in a significant increase in serum testosterone levels with parallel and appropriate increases in serum dihydrotestosterone (DHT) and estradiol $\left(\mathrm{E}_{2}\right)$ levels. After the first application of Androgel to hypogonadal men, serum testosterone levels rose into the normal range within $30 \mathrm{~min}$ followed by a gradual rise throughout the following 24 hours (Figure 1). By the end of 1st day, the levels attained were comparable with the subsequent steady-state pre-dose levels on the 3rd, 5th, and 7th days of application. Mean serum testosterone levels were four- to fivefold above the baseline levels and at the upper limit of the normal range for the duration of gel application (one site: $745.53 \pm 149.57 \mathrm{ng} / \mathrm{dL}$; four sites: $794.52 \pm 118.16$ ), and returned to baseline within four days after stopping application. These serum patterns were similar, irrespective of the number of sites of application. However, the application of testosterone gel at four sites resulted in an area under the curve of testosterone which was $23 \%$ higher compared to application of the same amount of gel at one site (although this difference did not achieve statistical significance). Swerdloff and colleagues ${ }^{25}$ demonstrated long-term pharmacokinetics of 1\% Androgel in 227 hypogonadal men. Subjects were assigned randomly to receive 5 or $10 \mathrm{~g}$ of Androgel or two nonscrotal patches. After 90 days of gel treatment, the dose was titrated up 


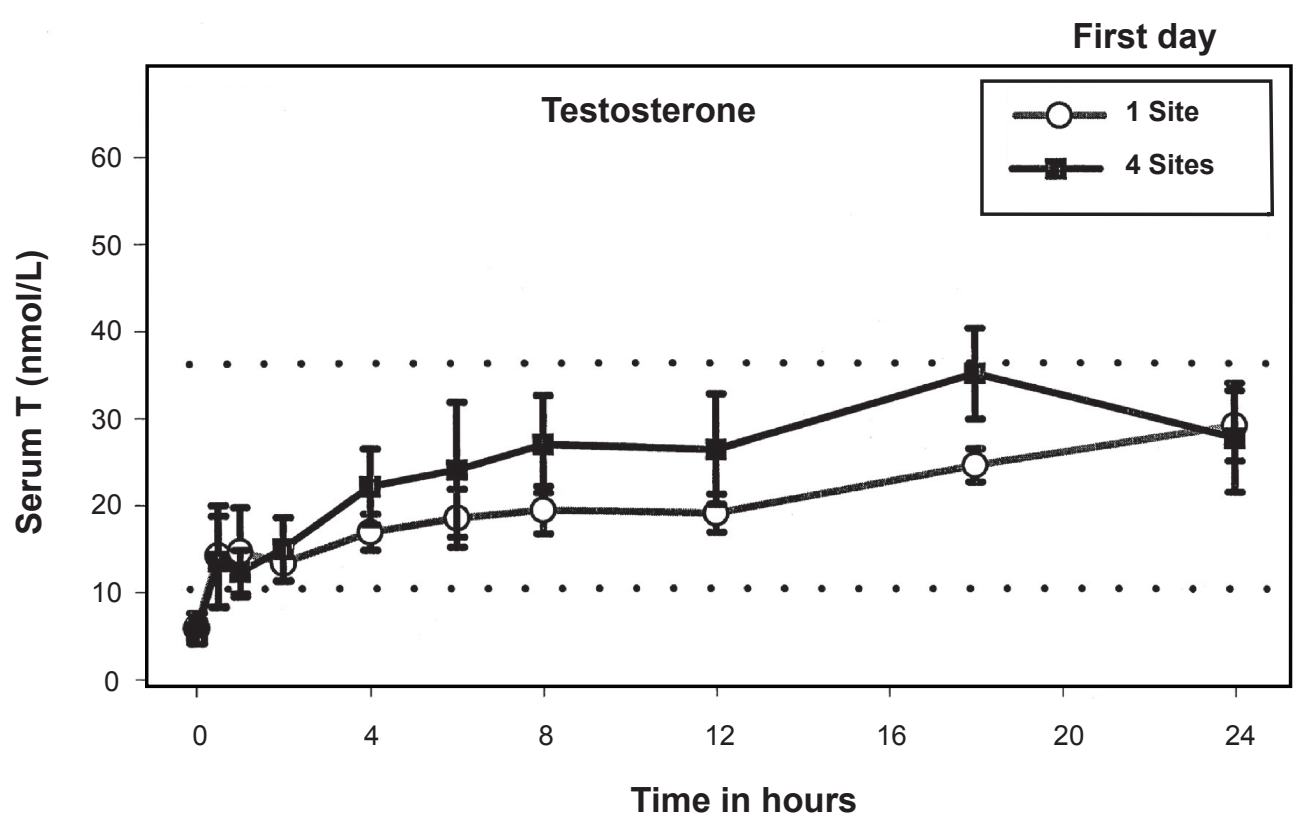

Figure I Serum T concentrations (mean \pm SEM) over $24 \mathrm{~h}$ after first application of $100 \mathrm{mg} \mathrm{T}$ gel. Reproduced with permission from Wang C, et al. J Clin Endocrinol Metab. 2000;85:964-969. ( The Endocrine Society.

(5 to $7.5 \mathrm{~g}$ ) or down (10 to $7.5 \mathrm{~g}$ ) if the serum testosterone levels were outside the normal range. On repeated application, mean serum levels of testosterone were maintained in the middle normal range with $5 \mathrm{~g}$ gel and in the upper normal range with the $10 \mathrm{~g}$ gel. Pharmacokinetics on days 30, 90, and 180 remained remarkably similar and steady levels of serum testosterone were maintained. On longer follow up of up to 32 months, serum concentrations of total testosterone and free testosterone increased dose dependently in the first 12 months; thereafter, testosterone levels did not appear to be different ${ }^{26}$ (Figure 2).

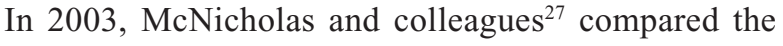
response of two doses of $1 \%$ Testim ( 5 or $10 \mathrm{~g} /$ day) to $5 \mathrm{mg}$ /day of Androderm patch in 208 hypogonadal men. Consistently throughout the study, Testim $10 \mathrm{~g} /$ day increased average, minimum, and maximum concentrations $\left(\mathrm{C}_{\text {avg }}, \mathrm{C}_{\min }\right.$, and $\mathrm{C}_{\max }$ ) more than both $5 \mathrm{~g} /$ day dose and Andropatch. At 90 days, the mean change from baseline with $10 \mathrm{~g} /$ day Testim was over three times greater than that with Andropatch $(P<0.001)$ and about twice as high as the $5 \mathrm{~g} /$ day Testim $(P<0.05)$. The results at 30 and 60 days were consistent with those at 90 days. The dose-dependent improvements in all pharmacokinetic profiles of testosterone gel in comparison to testosterone patch have been replicated in other studies. ${ }^{28-31}$

In a open-label crossover study of 30 hypogonadal men with human immunodeficiency virus (HIV), Scott

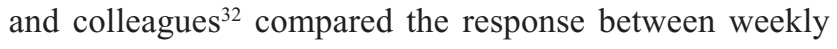
intramuscular (IM) testosterone (100-200 mg/week) and
$1 \%$ Androgel (5-10 g/day) for eight weeks. Peak levels of serum-free testosterone concentrations were significantly greater after IM testosterone $(42 \mathrm{pg} / \mathrm{mL})$ than after Androgel $(23 \mathrm{pg} / \mathrm{mL})(P<0.001)$. In addition, the peak-trough fluctuation in free testosterone was significantly greater after IM $(26.7 \pm 12.8 \mathrm{pg} / \mathrm{mL})$ than Androgel $(2.7 \pm 10.2 \mathrm{pg} / \mathrm{mL}$; $P<0.001)$. The percentage of patients who achieved therapeutic serum concentrations was 50\% during IM and $83 \%$ during Androgel therapy.

A randomized, crossover study was performed by Marbury and colleagues ${ }^{33}$ to compare the pharmacokinetic profiles of Testim and Androgel. Twenty-nine hypogonadal subjects received a single dose $(5 \mathrm{~g})$ of each formulation seven days apart. $\mathrm{C}_{\max }$ estimates for total testosterone, free testosterone, and dihydrotestosterone were greater $(30 \%$, $38 \%$, and $19 \%$, respectively) following the application of Testim compared to Androgel. Similarly, area under the curve (AUC; 0-24) estimates for total testosterone, free testosterone, and dihydrotestosterone were greater $(30 \%$, $47 \%$, and $11 \%$, respectively) following the application of Testim compared to Androgel.

In summary, the pharmacokinetic profile and the dose proportionality observed after testosterone gel application indicate that this transdermal delivery system raises serum testosterone levels into mid-high normal adult male range in a uniform and predictable manner. However, since inter- and intraindividual variations exist, it is prudent to monitor serum testosterone levels serially. 

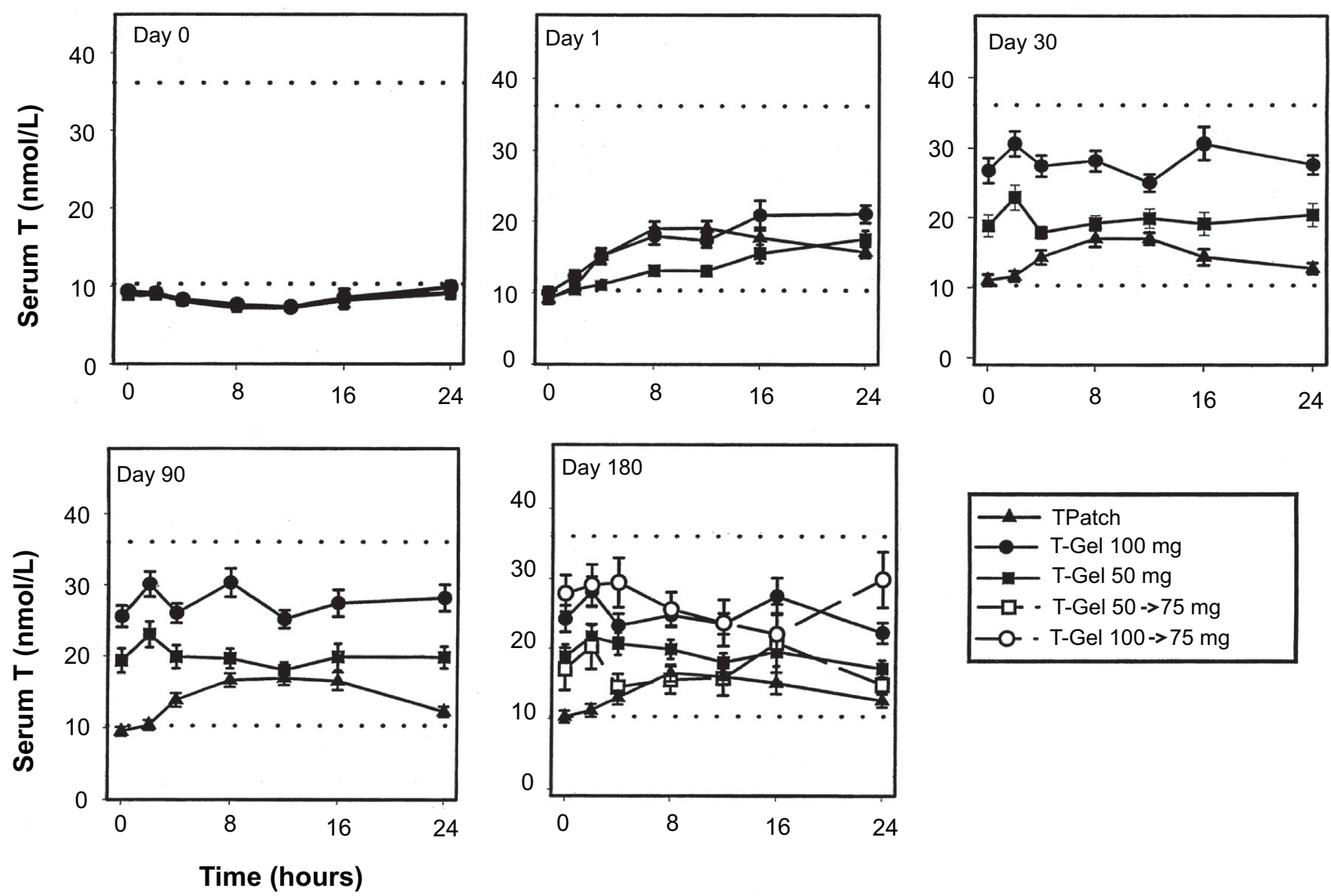

Figure 2 Serum T concentrations (mean 6SE) before (day 0) and after transdermal T applications on days I, 30, 90, and I80. Reproduced with permission from Swerdloff RS, et al. J Clin Endocrinol Metab. 2000;85:4500-45 I0. @ The Endocrine Society.

\section{Therapeutic efficacy}

The effects of testosterone gel on outcomes such as body composition, bone mineral density (BMD), sexual function, and cognition have been studied in several intervention trials (Table 1).

\section{Body composition}

The mechanisms by which hormones influence body composition, muscle strength, and physical performance are only partly understood. Possible biological mechanisms include the effects of testosterone on regulation of mesenchymal stem cell differentiation ${ }^{34,35}$ and muscle protein synthesis ${ }^{36,37}$ through androgen receptor-mediated pathways. ${ }^{35}$ Testosterone could also indirectly affect body composition through its effects on various inflammatory pathways. ${ }^{38-41}$

Wang and colleagues ${ }^{42}$ showed that after 90 days of treatment with $1 \%$ Androgel (5 or $10 \mathrm{~g} /$ day) or Androderm (5 $\mathrm{mg} /$ day), lean body mass (LBM) increased in all groups. However, the highest gains were seen in the $10 \mathrm{~g}$ /day group. Furthermore, reduction in fat mass (FM) and percent fat was only seen in the testosterone gel groups. On day 180, the changes in LBM and FM were maintained in the gel and patch groups. Similar changes in LBM and FM have been replicated in subsequent studies using $1 \%$ Testim. ${ }^{27,43}$ In an extension of their former study, Wang and colleagues ${ }^{26}$ followed hypogonadal patients receiving Androgel (5, 7.5, or $10 \mathrm{~g} /$ day) for an additional three years, and showed that LBM increased significantly from baseline and was maintained throughout the study period. The change in LBM was $1.97 \pm 0.24 \mathrm{~kg}$ at six months, which increased to $2.93 \pm 0.32$ $\mathrm{kg}$ at 18 months and $2.89 \pm 0.41 \mathrm{~kg}$ at 30 months $(P=0.0065)$. There was a concomitant decrease in FM. The decrease in FM was $0.8 \pm 0.3 \mathrm{~kg}$ at six months, $1.57 \pm 0.38$ at 18 months, and $1.30 \pm 0.51 \mathrm{~kg}$ at 30 months. However, neither LBM nor FM change was significantly different among the different dose groups nor was there was a significant increase in muscle strength (Figure 3).

\section{Bone density}

Testosterone may also directly affect bone tissue. Androgen receptors have been identified on both the osteoblastic and osteoclastic lineages as well as chondrocytes. ${ }^{44,45}$ Androgens 


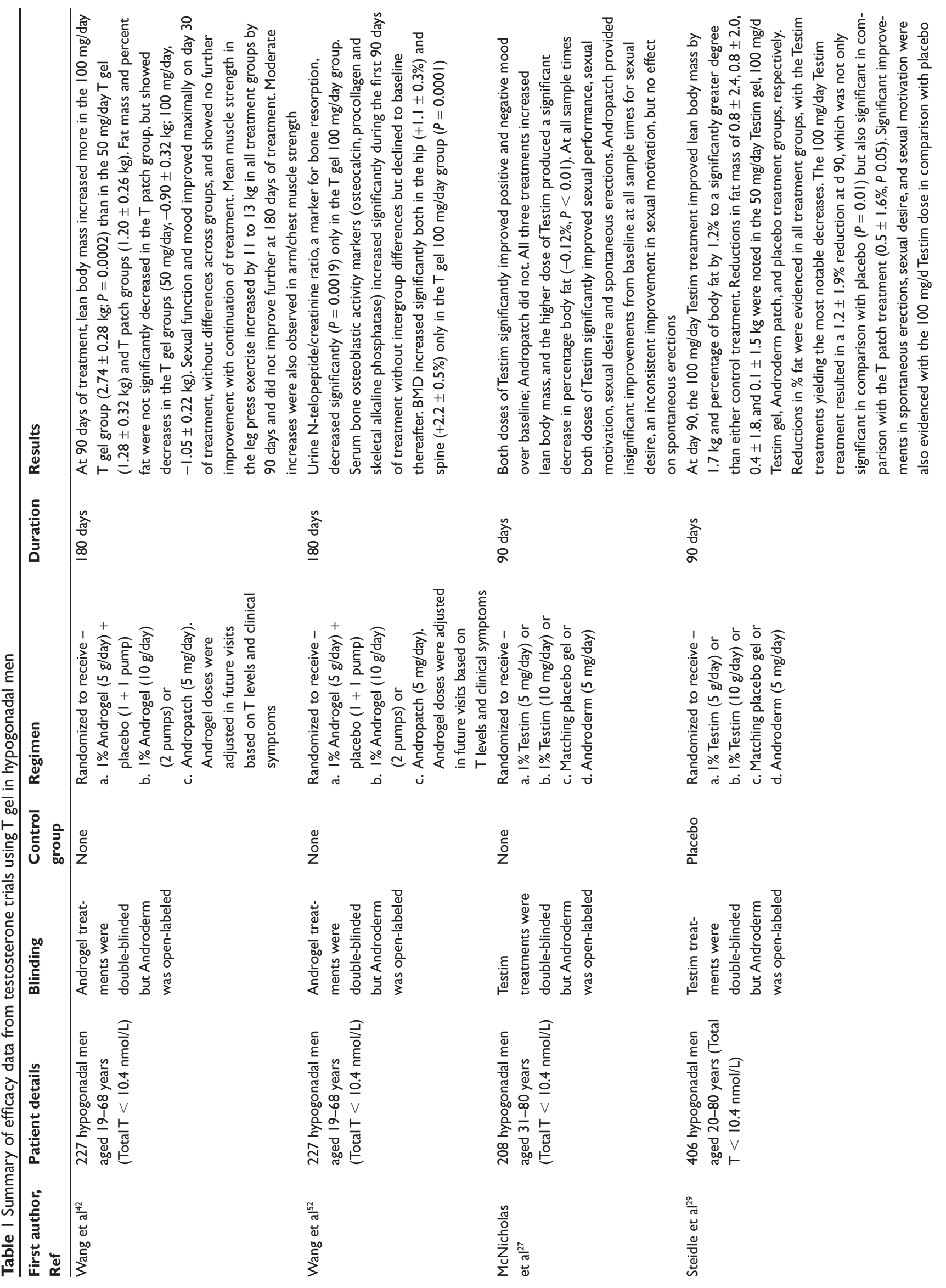



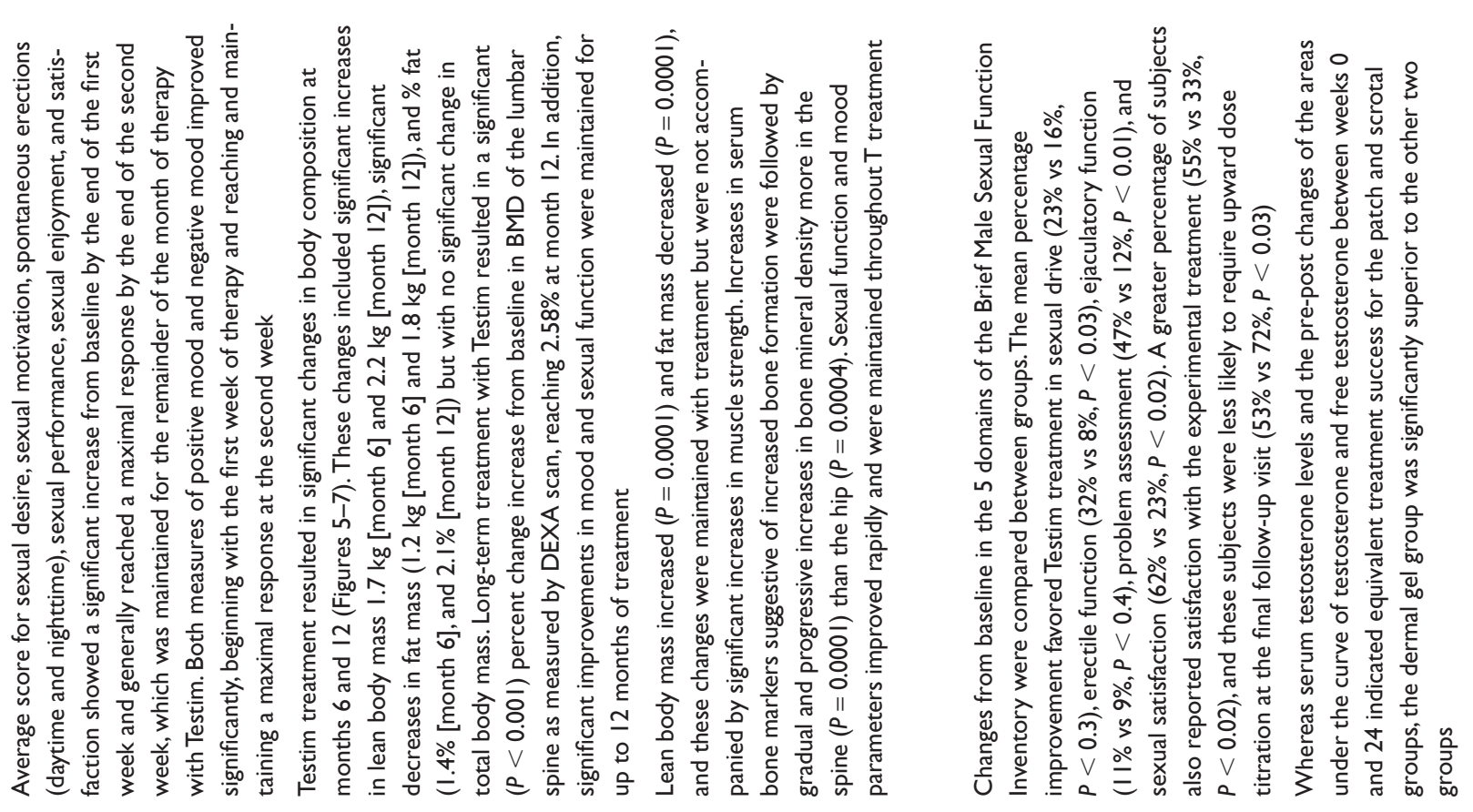

กิ

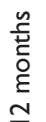

윰을

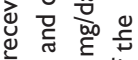

츨 종으

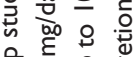

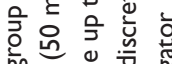

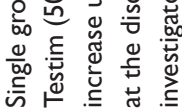

¿̊

Oั

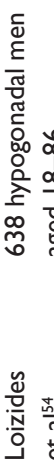

ฮั

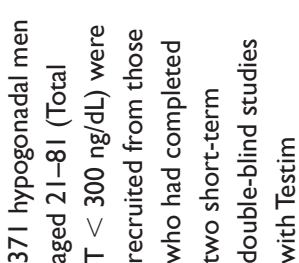

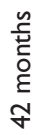

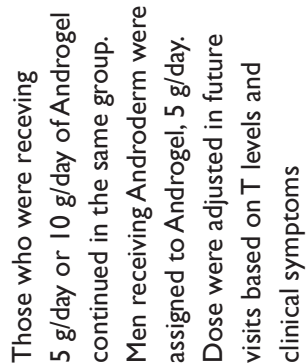

Zั $\underset{\substack{0 \\ ٍ}}{\stackrel{5}{3}}$

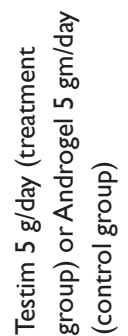

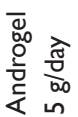

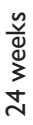

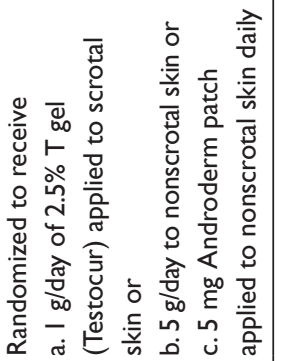

ํํำ

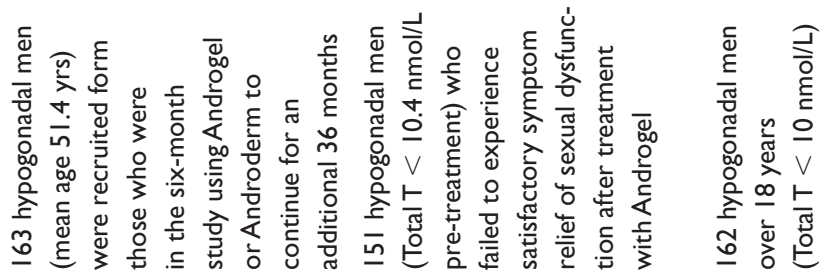

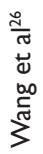

○ั

ญั

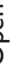




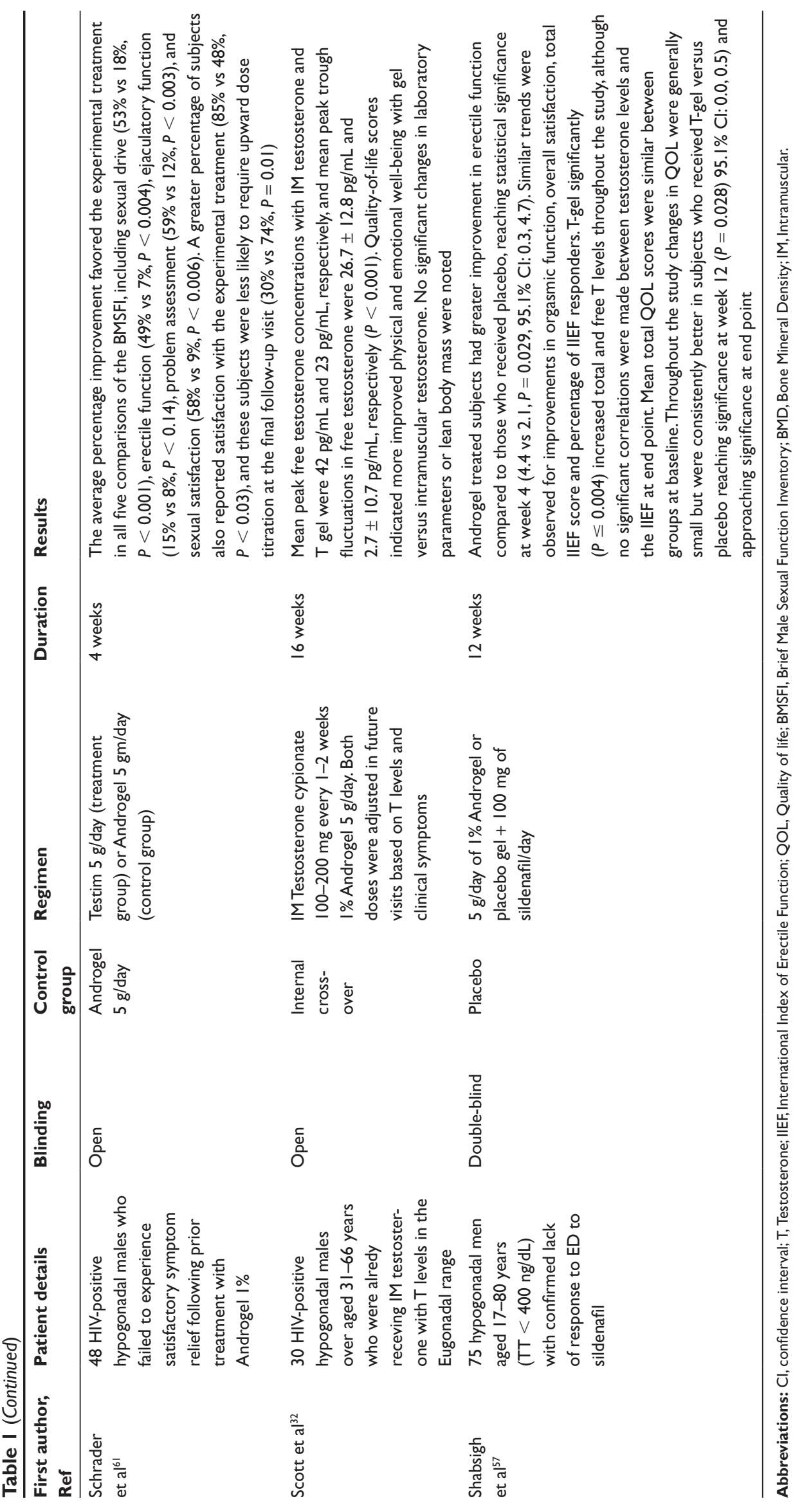


A

\section{B}

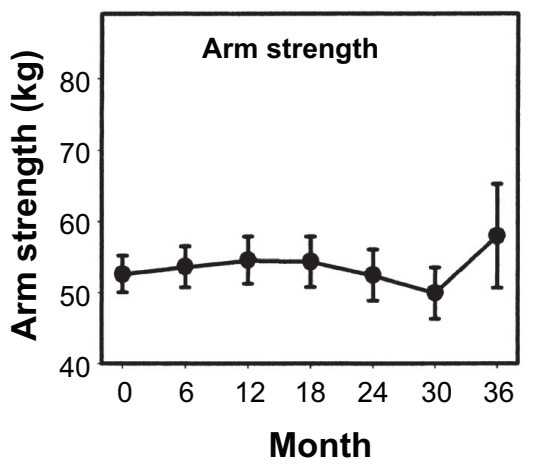

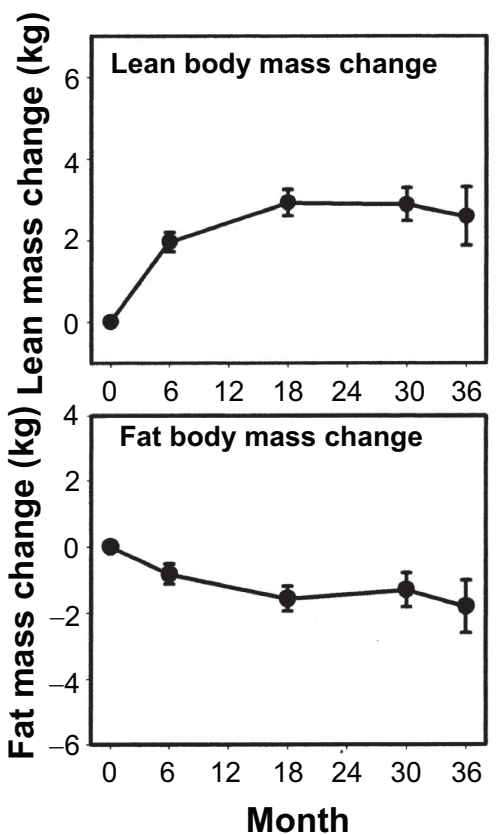

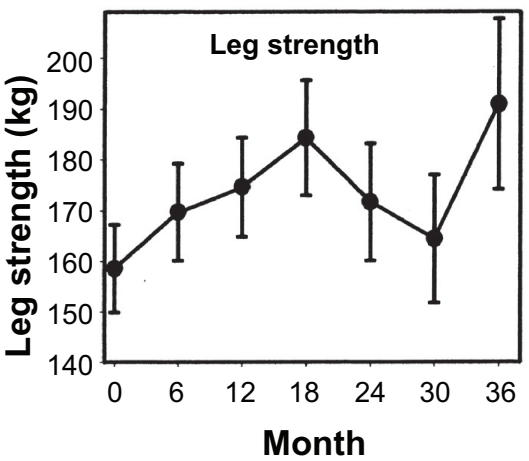

Figure 3 Changes in body composition A) and muscle strength B) during treatment with Androgel. Reproduced with permission from Wang C, et al.J Clin Endocrinol Metab. 2004;89:2085-2098. (C) The Endocrine Society.

exert proapoptotic effects on osteoclasts and antiapoptotic effects on osteoblasts and osteocytes. Testosterone also modulates the effects induced by other hormones and cytokines involved in bone metabolism. ${ }^{46}$ Testosterone exerts its influence on the (RANK)/osteoprotegerin (OPG) system ${ }^{47}$ and helps protect excessive bone resorption.$^{48}$ Additionally, testosterone appears to indirectly limit bone resorption by inhibiting the expression of interleukins 1 and $6^{49,50}$ and cytokines that induce bone resorption by promoting osteoclast activation and differentiation. Effects of testosterone on bone are also mediated via its conversion to estradiol. However, one recent study did not show adverse skeletal consequences by inhibiting aromatase by anastrazole. ${ }^{51}$

A number of randomized placebo-controlled trials, both short-term and long-term, of testosterone therapy on bone outcomes have been conducted. In a three-month study of testosterone replacement with Testim, ${ }^{27}$ no significant
BMD changes were observed, which confirms that a longer duration of treatment is needed to see considerable changes in BMD. Androgel application for six months was shown to decrease bone resorption markers and increase osteoblastic activity, resulting in a significant increase in BMD at the hip and spine.${ }^{52}$ In the three-year extension of this study, ${ }^{26}$ bone turnover markers confirmed that in the early phase there was a decrease in bone resorption and an increase in bone formation. However, in the later phase there was no further decrease in bone resorption. BMD continued to increase at the hip and spine after 6,18 , and 30 months of treatment (Figure 4). The long-term effects of Testim have been evaluated in open-label extensions of two studies involving a total of 371 hypogonadal men ${ }^{30}$ receiving Testim 5 or $10 \mathrm{~g}$ daily for up to 12 months. Analysis of BMD showed that long-term treatment with Testim was associated with an increase in BMD that appeared incremental with longer duration of therapy. 

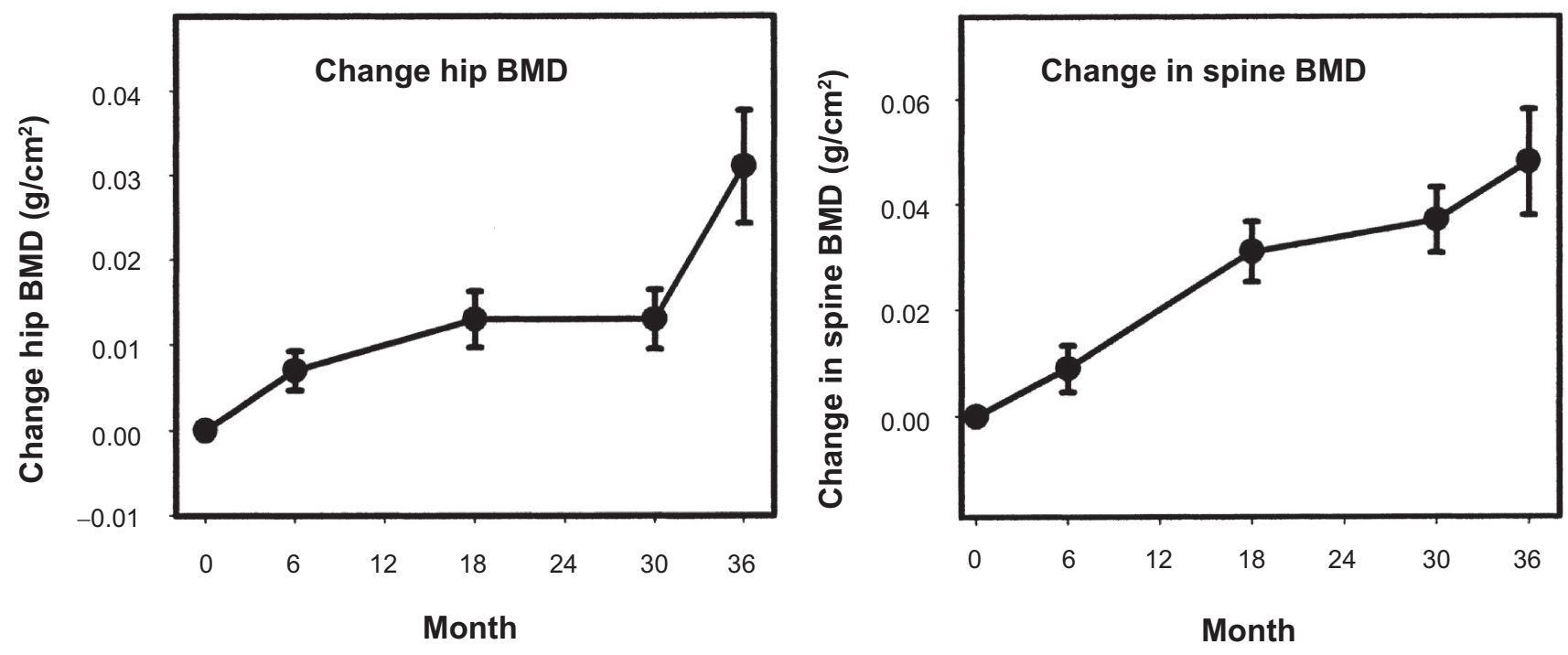

Figure 4 Changes in hip and spine bone mineral density (BMD) in hypogonadal men treated with Androgel. Reproduced with permission from Wang C, et al. J Clin Endocrinol Metab. 2004;89:2085-2098. (C) The Endocrine Society.

Long-term studies investigating the efficacy of testosterone gel therapy in reducing fracture risk are lacking.

\section{Sexual function}

Androgens have a role in several aspects of male sexual behavior such as libido, erectile function, and orgasms. ${ }^{53}$ Trials of testosterone gel replacement in hypogonadal men are consistent in showing an improvement in sexual function. In a one-month study designed specifically to explore the time to response in sexual activity after testosterone replacement, 638 hypogonadal men received 5 or $10 \mathrm{gm} / \mathrm{d}$ of Testim gel in an open-label fashion. ${ }^{54}$ After one week of Testim therapy, patients showed marked improvements in sexual function that continued to improve through week 2 and was maintained at week 4. Long-term studies using Androgel replacement in hypogonadal men ( 5 or $10 \mathrm{~g} /$ day) showed that sexual function (sexual desire, motivation, and sexual performance) increased in all treatment groups at 30 days and was maintained with continued use for three years. ${ }^{26}$ This and other data ${ }^{55,56}$ suggest that normalization of sexual function occurs once testosterone levels are restored to the lower adult male concentration range. Increasing serum testosterone levels to the upper normal range does not further improve sexual function. In a three-month study comparing $10 \mathrm{~g}$ Testim with Androderm and Andropatch, Steidle and colleagues ${ }^{29}$ treated 406 hypogonadal men. There was a significant improvement in mean scores for spontaneous erections, sexual motivation, sexual desire and sexual performance in men on Testim compared to placebo. Improvements in sexual function and libido were also evident in another three-month study of 208 patients. ${ }^{27}$ Both doses of Testim (5 g/day and $10 \mathrm{~g} / \mathrm{d}$ ) produced improvements in spontaneous erections, sexual desire, and performance. Additionally, compared to Andropatch, treatment with Testim gel was associated with more consistent improvements in sexual motivation throughout the 90-day period, with significant differences from baseline at all time points. The benefits of Testim therapy on patients' sexual function were also sustained over one year. ${ }^{30}$

The benefit of testosterone gel as an adjunct therapy to sildenafil in men with erectile dysfunction (ED) was demonstrated in a study of 75 hypogonadal men with confirmed lack of response to sildenafil monotherapy. ${ }^{57}$ Testosterone-treated subjects had greater improvement in erectile function compared to those who received placebo, reaching statistical significance at week $4(P=0.029)$. Similar trends were observed for improvements in orgasmic function, overall satisfaction and International Index of Erectile Function (IIEF) score.

\section{Mood}

Studies have shown that testosterone levels correlate with mood. There is historic evidence of a strong positive correlation of testosterone with parameters such as mental well being, joyfulness, social interactivity, general arousal reaction, and wakefulness. Negative correlations have been reported with depression, nervousness, irritability, and anxiety. ${ }^{53}$ 
In hypogonadal men receiving Androgel, positive mood parameters, such as sense of well being and energy level improved while negative parameters such as sadness and irritability decreased. The improvement in mood was observed on day 30 and was maintained with continued treatment for $\operatorname{six}^{42}$ and 36 months. ${ }^{26}$ The improvement in mood parameters was not dependent on the magnitude of increase in serum testosterone levels. In fact, once serum testosterone increased into the low normal range, maximal improvement in mood parameters was seen. Thus, improvement in mood (similar to sexual function) in response to testosterone therapy appears to be dependent on reaching a threshold of serum testosterone that lies in the low normal range. The same results were replicated with the use of Testim where mood improved early after institution of treatment that was maintained for the duration of the treatment up to three months ${ }^{27,29}$ and one year. ${ }^{30}$ In a short-term study with Testim, Loizides and colleagues ${ }^{54}$ showed that measures of positive and negative mood improved significantly, beginning with the first week of therapy and reaching a maximal response at the second week. Kuhnert and colleague ${ }^{28}$ have reported similar findings.

\section{Safety}

\section{Application site reactions}

The local tolerability of testosterone gel is superior to other transdermal products. In studies comparing testosterone gel with a testosterone patch, the incidence of adverse skin events has been significantly higher in the testosterone patch group. For instance, skin irritation was reported in $5.5 \%$ of subjects treated with Androgel and in $66 \%$ of subjects in the testosterone patch (Androderm) group in a six-month study of 227 hypogonadal men. ${ }^{20}$

The most commonly reported skin reactions were erythema and irritation at the application site. Upon longer follow up of approximately four years, skin irritation was minimal, did not appear to be dose dependant and was not a concerning cause for discontinuation. ${ }^{26}$ Both short- and longterm studies using Testim also confirm these findings. ${ }^{27,29,30}$

\section{Prostate}

Long-term treatment with testosterone gel has shown a good safety profile with respect to the prostate. In the longest published trial of testosterone gel in which 163 hypogonadal men were treated for up to 42 months with Androgel, ${ }^{26}$ the baseline mean prostate-specific antigen (PSA) level was $0.85 \pm 0.06 \mathrm{ng} / \mathrm{ml}$. Mean PSA at six months was $1.11 \pm 0.08 \mathrm{ng} / \mathrm{ml}$ and showed no significant increase with continued testosterone treatment $(P=0.150)$. Furthermore, there was no difference in serum PSA levels among the three testosterone gel dose groups (5, 7.5, and $10 \mathrm{~g} /$ day). Mean international prostate symptom scores (IPPS) were not increased in subjects on gels. One subject had transurethral resection of the prostate for lower urinary tract symptoms. Of the subjects who had elevated PSA during the study, three had confirmed prostate cancer on biopsy (all $>60$ years old). In a long-term trial of Testim in 371 hypogonadal men (5 and $10 \mathrm{~g} /$ day) ${ }^{30}$ baseline PSA concentrations were $1.26 \pm 0.05 \mathrm{ng} / \mathrm{mL}$. The change from baseline were significant at each of the visits $(0.39 \mathrm{ng} / \mathrm{mL}$ [month 3$], 0.37 \mathrm{ng} / \mathrm{mL}$ [month 6], and $0.45 \mathrm{ng} / \mathrm{mL}$ [month 12]). In this study, three patients were diagnosed with prostate cancer. Two of them were aged 63 and 73 years and underwent biopsies because of rising PSA values. The third subject was 53 years old and had a biopsy 60 days post-treatment because of an asymmetrical prostate on digital exam. Mean IPSS scores were not increased from baseline. Although short-term studies ${ }^{27,28,42}$ using Androgel or Testim have reported no cases of prostate cancer, one year ${ }^{30}$ and three year ${ }^{26}$ extensions of these studies have documented prostate cancer in a small number of subjects. In both short and long-term testosterone gel studies, PSA elevations of $4 \mathrm{ng} / \mathrm{mL}$ or greater have occurred only in a minority of individuals and many of them have either had normal PSA values on repeat measurements or normalization of PSA on discontinuation of testosterone or negative biopsies (in subjects who had persistent elevations in PSA despite treatment discontinuation). ${ }^{26-28}$ Meikle and colleagues showed in a one-year study of physiological testosterone replacement in hypogonadal men that PSA levels remained within the normal range, and that none of the subjects developed benign prostatic hyperplasia during therapy.$^{58}$

There is debate regarding cases of prostate cancer that are detected in trials involving long-term testosterone administration. Close monitoring of PSA in these trials, the heightened awareness of the investigators, and the rate of referral to a urologist for prostate biopsy be accountable for the increased detection of prostate cancer. There is also a concern that testosterone therapy may unmask asymptomatic occult prostate cancer. There still remains considerable uncertainty whether testosterone administration can lead to the growth and development of prostate cancer or if prostate cancer cases detected during therapy are coincidental to treatment.

\section{Hematocrit}

Increase in hematocrit (Hct) and hemoglobin ( $\mathrm{Hb})$ levels in clinical trials of testosterone replacement confirms the 
decade-old known effects of testosterone on erythropoesis. Long-term administration of $1 \%$ Androgel $(5,7.5$, or $10 \mathrm{~g} / \mathrm{d})$ for 36 months showed that $\mathrm{Hb}$ and Hct levels increased steadily until month 12 in a dose-dependent manner with the $10 \mathrm{~g} / \mathrm{d}$ group attaining the highest $\mathrm{Hb}$ and Hct concentrations. ${ }^{26}$ After 12 months there was no further increase in the levels. In the same study, 9\% of men achieved $\mathrm{Hb}$ levels above $18 \mathrm{~g} / \mathrm{dl}$ or Hct greater than $56 \%$ at some point during the study. In a 12-month study of $1 \%$ Testim in hypogonadal men, mean $\mathrm{Hb}$ and Hct values remained within the normal range. However, $2.4 \%$ of subjects showed an increased hematocrit beyond the acceptable range and were discontinued from the study. ${ }^{30}$ However, none of these studies examined if the response profile was significantly different in younger and older men.

\section{Skin transfer}

There is concern about the possibility of inadvertent interpersonal transfer of testosterone gel. In men, the bioavailability of applied testosterone gel is limited to $10 \%-15 \%$. Upon application, testosterone penetrates the skin, with alcohol acting as a permeation enhancer. When applied to the skin, the alcohol evaporates quickly leaving significant amount of testosterone on the skin. Hence, a large reservoir of testosterone is left on the skin with the potential to be transferred. ${ }^{59}$ Unpublished studies from manufacturers indicate that both Androgel and Testim have the potential to raise testosterone levels in women after skin contact with treated men even hours after application. Additionally with abdominal application of Testim, wearing a shirt did not completely prevent the transfer of testosterone to the partner in spite of covering the area with a shirt. As of May 7th 2009, the US Food and Drug Administration (FDA) has instructed testosterone gel manufactures to issue a "black box" warning regarding the potential for skin-to-skin transfer. ${ }^{60}$ This is a consequence of secondary exposure of children ranging in age from nine months to five years that were reported to the FDA. Adverse events reported in these children included enlargement of the genitalia, premature pubarche, advanced bone age, and aggressive behavior. Overall, covering the application site with clothing seems to minimize the risk of testosterone transfer during skin-to-skin contact. Even though there is paucity of cases reporting inter-personal transfer, the risk of transfer to women and children is possible. Hence, patient education is crucial.

\section{Monitoring treatment}

The goal of testosterone therapy should be to restore serum testosterone levels to the mid-normal range. In men receiving transdermal gel, testosterone level should be measured after patient has been on treatment for one to two weeks, ideally between two and six hours after gel application. Initial monitoring for symptom relief (improvement in libido, erectile function, energy and well being) should be performed three months after initiation of therapy. Failure to benefit from therapy within a reasonable time interval (3-6 months) should result in investigation for other causes of symptoms. ${ }^{6}$ A baseline BMD should be obtained in all hypogonadal men and repeated after one to two years of testosterone therapy to assess for interval changes in bone mass. ${ }^{5,6}$ Hematocrit should be measured at baseline, repeated at three months, and then annually. The Endocrine Society specifies a hematocrit cut-off of 54\% above which testosterone therapy should be discontinued. If hematocrit rises above this level, testosterone therapy should be stopped until hematocrit decreases to a safe level. The patient should be evaluated for hypoxia and sleep apnea, and therapy should be restarted at a reduced dose. A therapeutic phlebotomy at periodic intervals may be required in some cases. Digital examination of the prostate and PSA measurement should be performed before initiating treatment, at three months, and annually thereafter depending upon the regional practice pattern. PSA increments of $\geq 1.4 \mathrm{ng} / \mathrm{mL}$ above baseline in any one-year period should warrant urologic evaluation and consideration of prostate biopsy. If longitudinal PSA data are available for more than two years, PSA velocity can be calculated to assess risk of prostate cancer. PSA velocity of more than $0.4 \mathrm{ng} / \mathrm{ml} / \mathrm{year}$, using the PSA level after six months of testosterone administration as the reference, requires further urological evaluation. PSA velocity should be used only if there are longitudinal PSA data for more than two years.

\section{Androgel versus Testim}

Although Androgel and Testim have well-established therapeutic efficacies, comparison studies that exist in the literature might prompt the provider to use one more than the other. Short-term, open-label studies ${ }^{43,61}$ have demonstrated that in patients who failed to respond to Androgel, their libido, erectile and ejaculatory function, cognition, and overall sexual satisfaction significantly improved following a switch to Testim. In a larger study, the records of 370 hypogonadal men on testosterone gel therapy (Testim or Androgel) were reviewed to identify men who underwent a brand substitution due to suboptimal response. ${ }^{62}$ Approximately $20 \%$ of these 370 men underwent brand substitution. Of these, $83 \%(n=62)$ switched from Androgel to Testim. The predominant indication for gel substitution 


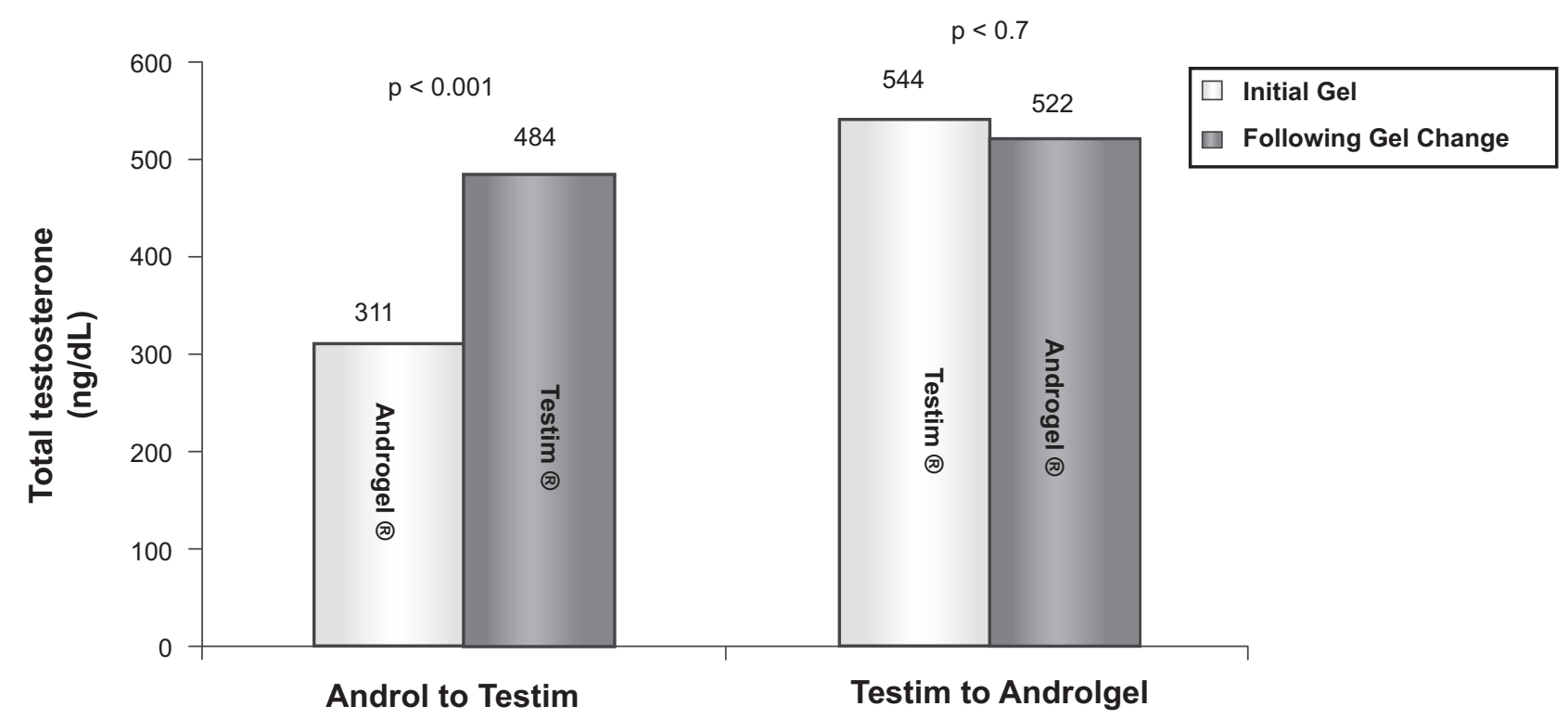

Figure 5 Total serum testosterone levels pre- and post-gel substitution. Reproduced with permission from Grober ED, et al. Efficacy of changing testosterone gel preparations (Androgel or Testim) among suboptimally responsive hypogonadal men. Int J Impot Res. 2008;20:213-217. @ Nature Publishing Group.

was either lack of improvement in symptoms or failure to achieve adequate serum levels. Following a change to Testim, mean total and free testosterone levels increased significantly (Figure 5) with only $17 \%$ of patients having total testosterone less than $300 \mathrm{ng} / \mathrm{dL}$ as compared to $58 \%$ while they were on Androgel. On the contrary, $17 \%$ of men $(n=13)$ switched from Testim to Androgel. The main indication for this substitution was the physical characteristics (scent and residue) of Testim. Following switch to Androgel, total testosterone levels remained below $300 \mathrm{ng} / \mathrm{dL}$ in $27 \%$ of these patients as compared to $15 \%$ while they were on Testim. These findings are probably explained by the differing pharmacokinetics of the two testosterone gels. The enhanced absorption of Testim is attributed to pentadecalactone, an emollient specific to Testim, which also accounts for the unique scent of the gel. ${ }^{33}$ In summary, although Testim appears to have a greater bioavailability than Androgel, this advantage is at the expense of undesirable physical properties such as its stickiness and smell. An easy option for Androgel users not achieving adequate serum testosterone levels would be to increase the dose rather than switching brands.

\section{Contraindications}

Baseline evaluation of hypogonadal men should include screening for conditions which could be exacerbated by testosterone therapy. Testosterone administration is contraindicated in men with prostate or breast cancer. Testosterone therapy should not be administered to men with a palpable prostate nodule (or induration), or if PSA is greater than $4 \mathrm{ng} / \mathrm{mL}$ (without a urological evaluation). Testosterone therapy should be administered carefully to men with benign prostatic hypertrophy and mild to moderate lower urinary tract symptoms. Men with severe lower urinary tract symptoms (IPSS symptom score $>19$ ) should undergo urological evaluation before consideration of testosterone therapy. Baseline assessment of prostate cancer risk is necessary in middle-aged and older men before instituting therapy. Age, race, family history of prostate cancer and PSA level - the major determinants of prostate cancer risk - should be factored in this risk assessment.

As testosterone therapy is expected to raise Hct, patients with baseline hematocrit $>50 \% 0^{5,6}$ should not be given testosterone. Testosterone administration can cause salt and water retention and exacerbate edema in men with uncontrolled congestive heart failure. Therefore, testosterone should not be administered in men with class III or IV congestive heart failure. Men with moderate or severe obstructive sleep apnea should be evaluated by a sleep specialist before testosterone therapy is instituted.

\section{Conclusion}

The favorable pharmacokinetic profile and treatment outcomes combined with enhanced tolerability and superior compliance suggests that testosterone gel formulations are a safe and effective treatment in men with hypogonadism. Studies suggest that the two commercially available gels, 
Androgel and Testim, are not bioequivalent and that Testim may have superior pharmacokinetic properties in comparison to Androgel. It appears that a brand substitution may be reasonable in nonresponders. While substitution from Androgel to Testim may result in higher testosterone levels and improved clinical responsiveness, a switch from Testim to Androgel may be needed in some subjects to eliminate the unwanted side effects related to the physical properties of the gel. However, it should be realized that trials comparing the efficacy of brand substitution to date have been unblinded. This methodological shortcoming compromises the quality of the findings as it is not known how much of an effect this bias would have on symptom amelioration.

The advantages of testosterone gel over the testosterone patch are a lower incidence of skin irritation, the ease of application, the invisibility of the gel, and the ability to deliver testosterone levels dose-dependently. Transdermal gel also gives stable testosterone levels while injectable testosterone esters are associated with "roller-coaster" pharmacokinetics where serum testosterone levels rise into the high normal or supraphysiological range immediately following injection, but fall into the hypogonadal range within two weeks. ${ }^{63,64}$ This is reflected in fluctuations in mood, energy, and sexual function. Injectable testosterone esters also result in a high incidence of polycythemia compared with gels due to higher circulating testosterone levels. Injectable testosterone undecanoate is a long-acting ester that maintains serum testosterone levels within the normal range without major fluctuations, and its longer half-life allows for administration every three months after an initial loading dose. ${ }^{65-67}$ This formulation is already in use in Europe and is awaiting FDA approval for use in the United States. However, a potential adverse effect of testosterone gel that should be borne in mind is the transfer risk to children and women upon close contact with the skin. Patient education is necessary.

\section{Disclosures}

The authors report no conflicts of interest in this work.

\section{References}

1. Araujo AB, O’Donnell AB, Brambilla DJ, et al. Prevalence and incidence of androgen deficiency in middle-aged and older men: estimates from the Massachusetts Male Aging Study. J Clin Endocrinol Metab. 2004;89(12):5920-5926.

2. Harman SM, Metter EJ, Tobin JD, Pearson J, Blackman MR. Longitudinal effects of aging on serum total and free testosterone levels in healthy men. Baltimore Longitudinal Study of Aging. J Clin Endocrinol Metab. 2001;86(2):724-731.

3. Araujo AB, Esche GR, Kupelian V, et al. Prevalence of symptomatic androgen deficiency in men. J Clin Endocrinol Metab. 2007;92(11): $4241-4247$.
4. Petak SM, Nankin HR, Spark RF, Swerdloff RS, Rodriguez-Rigau LJ. American Association of Clinical Endocrinologists Medical Guidelines for clinical practice for the evaluation and treatment of hypogonadism in adult male patients - 2002 update. Endocr Pract. 2002;8(6):440-456.

5. Bhasin S, Cunningham GR, Hayes FJ, et al. Testosterone therapy in adult men with androgen deficiency syndromes: an endocrine society clinical practice guideline. J Clin Endocrinol Metab. 2006;91(6):1995-2010.

6. Wang C, Nieschlag E, Swerdloff R, et al. Investigation, treatment and monitoring of late-onset hypogonadism in males: ISA, ISSAM, EAU, EAA and ASA recommendations. Eur J Endocrinol. 2008;159(5):507-514.

7. Zitzmann M, Faber S, Nieschlag E. Association of specific symptoms and metabolic risks with serum testosterone in older men. $J$ Clin Endocrinol Metab. 2006;91(11):4335-4343.

8. Kelleher S, Conway AJ, Handelsman DJ. Blood testosterone threshold for androgen deficiency symptoms. J Clin Endocrinol Metab. 2004;89(8):3813-3817.

9. Vermeulen A, Verdonck L, Kaufman JM. A critical evaluation of simple methods for the estimation of free testosterone in serum. J Clin Endocrinol Metab. 1999;84(10):3666-3672.

10. Södergard R, Backstrom T, Shanbhag V, Carstensen H. Calculation of free and bound fractions of testosterone and estradiol-17 beta to human plasma proteins at body temperature. J Steroid Biochem. 1982;16(6):801-810.

11. Rosner W, Auchus RJ, Azziz R, Sluss PM, Raff H. Position statement: Utility, limitations, and pitfalls in measuring testosterone: an Endocrine Society position statement. J Clin Endocrinol Metab. Feb 2007;92(2):405-413.

12. Simmer H SI. Arnold Adolph Berthold (1803-1861) Zur Erinnerung an den hundertsten Todestag des Begrunders der experimentellen. Endokrinologie Dtsch med Wschr. 1961;86:2186-2192.

13. Cussons AJ, Bhagat CI, Fletcher SJ, Walsh JP. Brown-Sequard revisited: a lesson from history on the placebo effect of androgen treatment. Med J Aust. 2002;177(11-12):678-679.

14. Vornoff S. Testicular grafting from ape to man. London, UK: Brentanos Ltd; 1920.

15. Nieschlag E, Behre HM, Nieschlag S. Testosterone: Action, deficiency, substitution. Cambridge, MA: Cambridge University Press; 2004. pp 14:405-406.

16. Junkman K. Uber protrahiert wirksame androgene. Arch Path Pharmacol. 1952;215:85-92.

17. Niechlag E, Mauss J, Coert A, Kicovic P. Plasma androgen levels in men after oral administration of testosterone or testosterone undecanoate. Acta Endocrinol. 1975;79:366-374.

18. Bals-Pratsch M, Knuth UA, Yoon YD, Nieschlag E. Transdermal testosterone substitution therapy for male hypogonadism. Lancet. 1986;2(8513):943-946.

19. Mazer NA, Heiber WE, Moellmer JF, et al. Enhanced transdermal delivery of testosterone: a new physiological approach for androgen replacement in hypogonadal men. J Control Release. 1992;19:347-362.

20. Wang C, Berman N, Longstreth JA, et al. Pharmacokinetics of transdermal testosterone gel in hypogonadal men: application of gel at one site versus four sites: a General Clinical Research Center Study. J Clin Endocrinol Metab. 2000;85(3):964-969.

21. Nieschlag E, Buchter D, Von Eckardstein S, Abshagen K, Simoni M, Behre HM. Repeated intramuscular injections of testosterone undecanoate for substitution therapy in hypogonadal men. Clin Endocrinol (Oxf). 1999;51(6):757-763.

22. Unimed-Pharmaceuticals Inc.; A Solvay Pharmaceuticals I, Company. AndroGel prescribing information for healthcare professionals. Marietta, GA: Solvay Pharmaceuticals, Inc.; 2004.

23. Auxilium Pharmaceuticals I. Testim prescribing information for healthcare professionals. Norristown, PA: Auxilium Pharmaceuticals; 2004.

24. Sitruk-Ware R. Transdermal delivery of steroids. Contraception. 1989;39(1):1-20.

25. Swerdloff RS, Wang C, Cunningham G, et al. Long-term pharmacokinetics of transdermal testosterone gel in hypogonadal men. J Clin Endocrinol Metab. 2000;85(12):4500-4510. 
26. Wang C, Cunningham G, Dobs A, et al. Long-term testosterone gel (AndroGel) treatment maintains beneficial effects on sexual function and mood, lean and fat mass, and bone mineral density in hypogonadal men. J Clin Endocrinol Metab. 2004;89(5):2085-2098.

27. McNicholas TA, Dean JD, Mulder H, Carnegie C, Jones NA. A novel testosterone gel formulation normalizes androgen levels in hypogonadal men, with improvements in body composition and sexual function. BJU Int. 2003;91(1):69-74.

28. Kuhnert B, Byrne M, Simoni M, et al. Testosterone substitution with a new transdermal, hydroalcoholic gel applied to scrotal or non-scrotal skin: a multicentre trial. Eur J Endocrinol. 2005;153(2):317-326.

29. Steidle C, Schwartz S, Jacoby K, Sebree T, Smith T, Bachand R. AA2500 Testosterone gel normalizes androgen levels in aging males with improvements in body composition and sexual function. J Clin Endocrinol Metab. 2003;88(6):2673-2681.

30. Dean JD, Carnegie C, Rodzvilla J, Smith T. Long-term effects of testim(r) $1 \%$ testosterone gel in hypogonadal men. Rev Urol. 2004;6(Suppl 6):S22-S29.

31. Mazer N, Bell D, Wu J, Fischer J, Cosgrove M, Eilers B. Comparison of the steady-state pharmacokinetics, metabolism, and variability of a transdermal testosterone patch versus a transdermal testosterone gel in hypogonadal men. J Sex Med. 2005;2(2):213-226.

32. Scott JD, Wolfe PR, Anderson P, Cohan GR, Scarsella A. Prospective study of topical testosterone gel (AndroGel) versus intramuscular testosterone in testosterone-deficient HIV-infected men. HIV Clin Trials. 2007;8(6):412-420.

33. Marbury T, Hamill E, Bachand R, Sebree T, Smith T. Evaluation of the pharmacokinetic profiles of the new testosterone topical gel formulation, Testim, compared to AndroGel. Biopharm Drug Dispos. 2003;24(3):115-120.

34. Bhasin S, Calof OM, Storer TW, et al. Drug insight: Testosterone and selective androgen receptor modulators as anabolic therapies for chronic illness and aging. Nat Clin Pract Endocrinol Metab. 2006;2(3): 146-159.

35. Singh R, Artaza JN, Taylor WE, et al. Testosterone inhibits adipogenic differentiation in 3T3-L1 cells: nuclear translocation of androgen receptor complex with beta-catenin and T-cell factor 4 may bypass canonical Wnt signaling to down-regulate adipogenic transcription factors. Endocrinology. 2006;147(1):141-154.

36. Brodsky IG, Balagopal P, Nair KS. Effects of testosterone replacement on muscle mass and muscle protein synthesis in hypogonadal men - a clinical research center study. J Clin Endocrinol Metab. 1996;81(10):3469-3475.

37. Ferrando AA, Sheffield-Moore M, Yeckel CW, et al. Testosterone administration to older men improves muscle function: molecular and physiological mechanisms. Am J Physiol Endocrinol Metab. 2002;282(3):E601-E607.

38. Cesari M, Penninx BW, Pahor M, et al. Inflammatory markers and physical performance in older persons: the InCHIANTI study. J Gerontol A Biol Sci Med Sci. 2004;59(3):242-248.

39. Kapoor D, Clarke S, Stanworth R, Channer KS, Jones TH. The effect of testosterone replacement therapy on adipocytokines and C-reactive protein in hypogonadal men with type 2 diabetes. Eur J Endocrinol. 2007;156(5):595-602.

40. Maggio M, Basaria S, Ble A, et al. Correlation between testosterone and the inflammatory marker soluble interleukin-6 receptor in older men. J Clin Endocrinol Metab. 2006;91(1):345-347.

41. Page ST, Herbst KL, Amory JK, et al. Testosterone administration suppresses adiponectin levels in men. J Androl. 2005;26(1):85-92.

42. Wang C, Swerdloff RS, Iranmanesh A, et al; Testosterone Gel Study Group. Transdermal testosterone gel improves sexual function, mood, muscle strength, and body composition parameters in hypogonadal men. J Clin Endocrinol Metab. 2000;85(8):2839-2853.

43. Steidle C, Witt MA, Matrisciano J, Block JE. Sexual functioning and satisfaction in nonresponders to testosterone gel: Potential effectiveness of retreatment in hypogonadal males. Clin Cornerstone. 2005;7(Suppl 4): S20-S25.
44. Colvard DS, Eriksen EF, Keeting PE, et al. Identification of androgen receptors in normal human osteoblast-like cells. Proc Natl Acad Sci US A. 1989;86(3):854-857.

45. Pederson L, Kremer M, Judd J, et al. Androgens regulate bone resorption activity of isolated osteoclasts in vitro. Proc Natl Acad Sci U S A. 1999;96(2):505-510.

46. Chen Q, Kaji H, Sugimoto T, Chihara K. Testosterone inhibits osteoclast formation stimulated by parathyroid hormone through androgen receptor. FEBS Lett. 2001;491(1-2):91-93.

47. Khosla S. Minireview: the OPG/RANKL/RANK system. Endocrinology 2001;142(12):5050-5055.

48. Boyce BF, Xing L. Functions of RANKL/RANK/OPG in bone modeling and remodeling. Arch Biochem Biophys. 2008;473(2):139-146.

49. Hofbauer LC, Ten RM, Khosla S. The anti-androgen hydroxyflutamide and androgens inhibit interleukin- 6 production by an androgenresponsive human osteoblastic cell line. J Bone Miner Res. 1999;14(8): 1330-1337.

50. Pilbeam CC, Raisz LG. Effects of androgens on parathyroid hormone and interleukin-1-stimulated prostaglandin production in cultured neonatal mouse calvariae. J Bone Miner Res. 1990;5(11): 1183-1188.

51. Leder BZ, Finkelstein JS. Effect of aromatase inhibition on bone metabolism in elderly hypogonadal men. Osteoporos Int. 2005; 16(12):1487-1494.

52. Wang C, Swerdloff RS, Iranmanesh A, et al. Effects of transdermal testosterone gel on bone turnover markers and bone mineral density in hypogonadal men. Clin Endocrinol (Oxf). 2001;54(6): 739-750.

53. Nieschlag E, Behre HM. Testosterone: Action, Deficiency, Substitution. Cambridge, MA: Cambridge University Press; 2004.

54. Loizides E, Swierzewski MJ, O’Neill C, Griesser J, Smith T. Early response time in sexual activity and mood following testosterone gel replacement in hypogonadal males from the Testim(R) START Study. Rev Urol. 2004;6(Suppl 6):S16-S21.

55. Bhasin S, Woodhouse L, Casaburi R, et al. Testosterone dose-response relationships in healthy young men. Am J Physiol Endocrinol Metab. 2001;281(6):E1172-E1181.

56. Seftel AD, Mack RJ, Secrest AR, Smith TM. Restorative increases in serum testosterone levels are significantly correlated to improvements in sexual functioning. J Androl. 2004;25(6):963-972.

57. Shabsigh R, Kaufman JM, Steidle C, Padma-Nathan H. Randomized study of testosterone gel as adjunctive therapy to sildenafil in hypogonadal men with erectile dysfunction who do not respond to sildenafil alone. J Urol. 2008;179(5 Suppl):S97-S102.

58. Meikle AW, Arver S, Dobs AS, et al. Prostate size in hypogonadal men treated with a nonscrotal permeation-enhanced testosterone transdermal system. Urology. 1997;49(2):191-196.

59. de Ronde W. Hyperandrogenism after transfer of topical testosterone gel: case report and review of published and unpublished studies. Hum Reprod. 2009;24(2):425-428.

60. Food and Drug Administration. Testosterone gel safety concerns prompt FDA to require label changes, medication guide. Available from: http://www.fda.gov/bbs/topics/NEWS/2009/NEW02011.html.

61. Schrader S, Mills A, Scheperle M, Block JE. Improvement in sexual functioning and satisfaction in nonresponders to testosterone gel: clinical effectiveness in hypogonadal, HIV-positive males. Clin Cornerstone. 2005;7 Suppl 4:S26-S31.

62. Grober ED, Khera M, Soni SD, Espinoza MG, Lipshultz LI. Efficacy of changing testosterone gel preparations (Androgel or Testim) among suboptimally responsive hypogonadal men. Int J Impot Res. 2008;20(2):213-217.

63. Nieschlag E, Cuppers HJ, Wiegelmann W, Wickings EJ. Bioavailability and LH-suppressing effect of different testosterone preparations in normal and hypogonadal men. Horm Res. 1976;7(3):138-145.

64. Snyder PJ, Lawrence DA. Treatment of male hypogonadism with testosterone enanthate. J Clin Endocrinol Metab. 1980;51(6): 1335-1339. 
65. Partsch CJ, Weinbauer GF, Fang R, Nieschlag E. Injectable testosterone undecanoate has more favourable pharmacokinetics and pharmacodynamics than testosterone enanthate. Eur J Endocrinol. 1995;132(4):514-519.

66. Schubert M, Minnemann T, Hubler D, et al. Intramuscular testosterone undecanoate: pharmacokinetic aspects of a novel testosterone formulation during long-term treatment of men with hypogonadism. J Clin Endocrinol Metab. 2004;89(11):5429-5434.
67. Minnemann T, Schubert M, Freude S, et al. Comparison of a new long-acting testosterone undecanoate formulation vs testosterone enanthate for intramuscular androgen therapy in male hypogonadism. $J$ Endocrinol Invest. 2008;31(8):718-723.

\section{Publish your work in this journal}

Clinical Interventions in Aging is an international, peer-reviewed journal focusing on evidence-based reports on the value or lack thereof of treatments intended to prevent or delay the onset of maladaptive correlates of aging in human beings. This journal is indexed on PubMed Central, MedLine, the American Chemical Society's 'Chemical
Abstracts Service' (CAS), Scopus and the Elsevier Bibliographic databases. The manuscript management system is completely online and includes a very quick and fair peer-review system, which is all easy to use. Visit http://www.dovepress.com/testimonials.php to read real quotes from published authors

Submit your manuscript here: http://www.dovepress.com/clinical-interventions-in-aging-journal 